\title{
АНАЛИЗ РИСКОВ ДЕИНДУСТРИАЛИЗАЦИИ В РФ
}

\author{
Комкина Т.A.
}

Целью работы является анализ развития основных укрупненных направлений обрабатывающих отраслей производства России с иелью выявления рисков, вызываемых деиндустриализацией.

DOI: $10.20537 /$ mce2019econ03

Введение. Промышленное производство является основой для экономического развития страны. Проводимая в России в 1990-х гг. экономическая политика привела к сокращению доли промышленного производства в ВВП относительно других отраслей, в первую очередь секторов торговли и услуг. Этому способствовали объективные причины, потери трудовых ресурсов и технологических ресурсов промышленности. Все это привело к возникновению рисков замедления ускоренного развития научно-технического прогресса, дисбалансу в развитии регионов страны, снижению уровня обороноспособности государства [1-4].

Для оценки рисков развития промышленного производства РФ был проведен анализ развития основных отраслей обрабатывающей промышленности: производство машин и оборудовании, химическое производство, целлюлозно-бумажное производство, издательская и полиграфическая деятельность, производство транспортных средств и оборудования, производство текстильной и швейной продукции, производство основных видов изделий из кожи и обуви. При проведении анализа тенденций развития промышленного производства РФ были учтены изменения классификатора, так как в 2010 г. Росстат перешел от использования Общероссийского классификатора продукции (ОКП) к Общероссийскому классификатору продукции по видам экономической деятельности (ОКПД). В связи с этим по некоторым позициям имелась возможность построить непрерывные временные ряды за весь период 1990-2016 гг., а по некоторым — с разбивкой на два периода 1990-2009 гг., либо 2010-2016 гг.

Анализ данных по обрабатывающей промышленности России. В результате произошедшей деиндустриализации в России сократилась доля обрабатывающей промышленности в ВВП относительно других от- 
раслей, в первую очередь секторов сферы услуг. В последние годы в развитых странах также произошло изменение отраслевой структуры экономики, снизилась доля промышленного сектора (до 25\% в среднем) и значительно выросла доля высокотехнологичных секторов сферы услуг [5]. Однако в России обрабатывающая промышленность, не достигнув показателей развитых стран, уступила лидирующие позиции операциям с недвижимостью - $17.3 \%$ ВВП, а также оптовой и розничной торговле - $15.8 \%$. При этом доля обрабатывающего производства в структуре ВВП страны в 2016 г. составила $13.7 \%$ (в 1989 г. - 32\%, в 2008 г. - 16.5\%) [6].

Одним из наиболее значимых видов деятельности обрабатывающих производств в РФ по удельному весу в общем объеме отгруженных товаров является производство машин и оборудования - $19.5 \%$, уступая только производству кокса и нефтепродуктов - $21.3 \%$ (см. табл. 1). Следует отметить, что в Германии доля производства машин и оборудования в структуре обрабатывающих производств составляет $42.8 \%$, в Японии - 42.2\%, в Китае $32.9 \%$, в США - $28.5 \%$. В связи с этим целесообразно в работе более подробно проанализировать данные по производству машин и оборудования в РФ.

Таблица 1. Структура обрабатывающей промышленности по укрупненным направлениям по объему отгруженных товаров 2016 г., \%, расчет по данным [5].

\begin{tabular}{|l|c|}
\hline \multicolumn{1}{|c|}{ Укрупненное направление } & \% \\
\hline Производство кокса и нефтепродуктов & 21.3 \\
\hline Производство машин и оборудования & 19.5 \\
\hline Производство пищевых продуктов, включая напитки, и табака & 17.7 \\
\hline $\begin{array}{l}\text { Металлургическое производство и производство готовых металличе- } \\
\text { ских изделий }\end{array}$ & 16.3 \\
\hline $\begin{array}{l}\text { Химическое производство, производство резиновых и пластмассовых } \\
\text { изделий }\end{array}$ & 10.5 \\
\hline $\begin{array}{l}\text { Обработка древесины и производство изделий из дерева, целлюлозно- } \\
\text { бумажное производство; издательская и полиграфическая деятельность }\end{array}$ & 4.4 \\
\hline Производство прочих неметаллических минеральных продуктов & 3.8 \\
\hline $\begin{array}{l}\text { Текстильное и швейное производство, производство кожи, изделий из } \\
\text { кожи и производство обуви }\end{array}$ & 1 \\
\hline Прочие & 5.5 \\
\hline
\end{tabular}


Анализ показателей производства машин и оборудования в РФ. Главным сдерживающим фактором развития машиностроения с 1992 г. выступает сокращение инвестиций, высокий износ основных производственных фондов, устаревшие технологии. По некоторым оценкам, в настоящее время в машиностроении используется лишь 10-15\% мощностей из имевшихся на начало 1992 г. [7]. Только за период 2010-2016 гг. уровень использования среднегодовой производственной мощности предприятий машиностроения снизился на 8.5\% [6], а также ухудшилось внешнеторговое сальдо по продукции машиностроения: если в 1995 г. объем импорта превышал объем экспорта на $23.4 \%$, то в 2016 г. — на $38.6 \%$ (см. рис. 1 ).

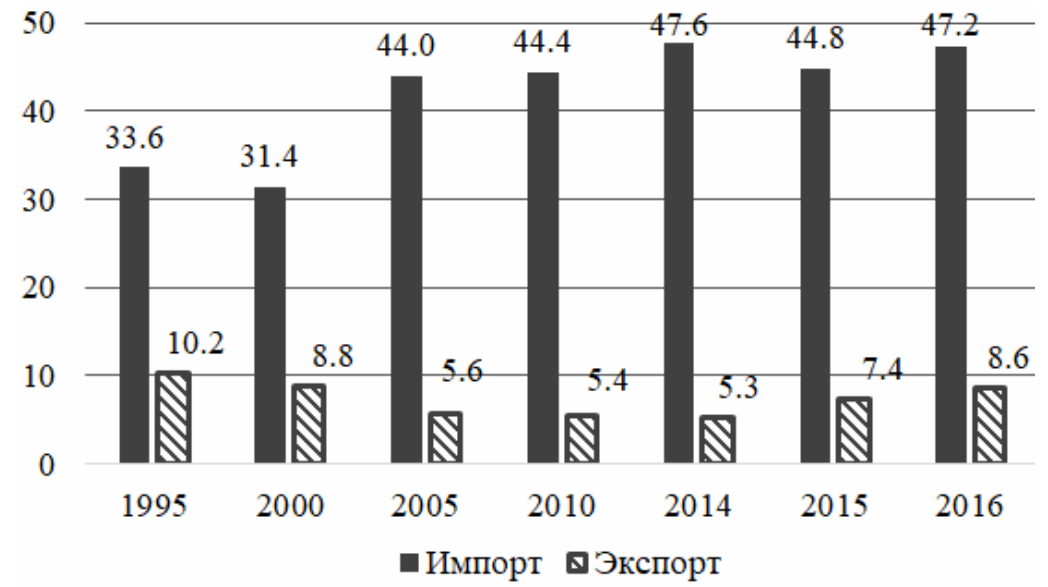

Рис. 1. Динамика доли экспорта из РФ и импорта в РФ машин, оборудования и транспортных средств, \%.

В 2017 г. основными странами-поставщиками импортных машин и оборудования в РФ являлись Китай (26\%), Германия (12\%) и США (8\%). Снижение экспорта машиностроения вызвано как внешними факторами (разрушение отраслевой специализации в структуре СЭВ и СССР, низкая конкурентоспособность выпускаемой продукции), так и внутренними факторами (изменение соотношения цен производителей сырьевых и обрабатывающих отраслей, приближение к мировому уровню цен факторов производства машиностроительной продукции, за исключением труда). 
Особые риски создаются значительным снижением производства инвестиционного оборудования, в первую очередь, станкостроения, где сокращение производства наблюдается практически по всем позициям: металлорежущие станки (шт.) - 2.6\% в 2009 г. и 5.9\% в 2016 г. относительно 1990 г.; станки токарные с числовым программным управлением (шт.) $1.3 \%$ и $2 \%$ соответственно; кузнечно-прессовые машины (шт.) - $4.8 \%$ и $11 \%$ соответственно; линии автоматические и полуавтоматические для машиностроения и металлообработки (комплектов) - 0.4\% в 2009 г.; прокатное оборудование (т) - 40\% в 2016 г. относительно 2010 г. При этом наблюдался рост производства сталеплавильного оборудования и литейных машин (т) - 136\% в 2016 г. относительно 2010 г. Сводный индекс по трем первым позициям относительно 1990 г. составил в 2016 г. $5.1 \%$ (см. табл. 2). В настоящее время российские производители станков занимают менее $10 \%$ внутреннего рынка, а производители инструмента для станков около 40\%. Уровень импортозависимости в подотрасли остается стабильным на уровне $90 \%$.

Таблица 2. Динамика выпуска металлообрабатывающего оборудования и оборудования для металлургической промышленности за период 1990-2016 гг., $1990=100 \%$, расчет по данным [6].

\begin{tabular}{|c|l|c|c|c|c|c|c|}
\hline № & Показатели & $\mathbf{1 9 9 0}$ & $\mathbf{1 9 9 5}$ & $\mathbf{2 0 0 0}$ & $\mathbf{2 0 0 9}$ & $\mathbf{2 0 1 0}$ & $\mathbf{2 0 1 6}$ \\
\hline 1 & Металлорежущие станки (шт.) & 100 & 24.3 & 12 & 2.6 & 3.8 & 5.9 \\
\hline 2 & $\begin{array}{l}\text { Станки токарные с числовым } \\
\text { программным управлением } \\
\text { (шт.) }\end{array}$ & 100 & 1.7 & 1.1 & 1.3 & 0.8 & 2 \\
\hline 3 & $\begin{array}{l}\text { Кузнечно-прессовые машины } \\
\text { (шт.) }\end{array}$ & 100 & 8.1 & 4.4 & 4.8 & 8.1 & 11 \\
\hline & Сводный индекс (1-3) & 100 & 6.9 & 3.8 & 2.5 & 2.9 & 5.1 \\
\hline & $\begin{array}{l}\text { Линии автоматические и по- } \\
\text { луавтоматические для маши- } \\
\text { ностроения и металлообра- } \\
\text { ботки (комплектов) }\end{array}$ & 100 & 10.3 & 2 & 0.4 & $\ldots$ & $\ldots$ \\
\hline 5 & $\begin{array}{l}\text { Сталеплавильное оборудова- } \\
\text { ние и литейные машины (т) }\end{array}$ & $\ldots$ & $\ldots$ & $\ldots$ & $\ldots$ & 100 & 136 \\
\hline 6 & Прокатное оборудование (т) & $\ldots$ & $\ldots$ & $\ldots$ & $\ldots$ & 100 & 40 \\
\hline
\end{tabular}

Также наблюдается сокращение производства энергетического оборудования и насосов: выпуск турбин (кВТ) всего составил 59.2\% в 2009 г. и $26.4 \%$ в 2016 г. относительно 1990 г.; в том числе в период 2010-2016 гг. 
снизилось производство турбин на водяном паре и турбин паровых прочих - 19\% в 2016 г. относительно 2010 г., турбин гидравлических и колес водяные - 40\%, турбин газовых (кроме двигателей турбореактивных и турбовинтовых) - 61.9\%; производство насосов центробежных, паровых и приводных (шт.) снизилось до 28.2\% в 2009 г. относительно 1990 г. (при этом в 2016 г. относительно 2010 г. несколько возросло производство насосов центробежных для перекачки жидкостей, прочих насосов, подъемников жидкостей - 106.7\%); выпуск дизелей и дизельгенераторов (шт.) составил всего 7.3\% в 2009 г. относительно 1990 г. При этом импорт насосов составляет последние года 58-63\% от объёма продаж. Основной объем продаж насосов приходится на нефтегазовую отрасль $(52.3 \%)$, водное хозяйство (22.8\%), энергетику (7.2\%) [7].

Производство кранов башенных (шт.) составило всего $1.5 \%$ в 2009 г. и $1.3 \%$ в 2016 г. относительно 1990 г., кранов мостовых электрических (включая специальные) - 15\% в 2009 г. относительно 1990 г. При этом производство лифтов возросло и составило 134\% в 2016 г. относительно 2010 г. Около 60\% рынка составляют лифты российского производства, 80\% комплектующих для лифтов также производятся в России (загрузка мощностей предприятий составляет около 40-50\%). В настоящее время объем рынка лифтов составляет 36 тыс. шт., предполагается, что в ближайшие 5 лет объем внутреннего рынка увеличится до 60 тыс. шт. (следует учитывать, что парк лифтов изношен более чем на 75\%) [8].

Сокращение производства техники для агропромышленного комплекса наблюдается по всем показателям за рассматриваемый период времени. Сводный индекс по всем позициям относительно 1990 г. составил в 2016 г. всего 7.2\%. Уровень инвестиций предприятий сельхозмашиностроения в НИОКР по отрасли в 2016 г. составил $0.67 \%$ от выручки (показатель ведущих предприятий отрасли более 4\%) [9]. Средний объем приобретения сельхозтехники за последние 5 лет примерно в 3 раза ниже потенциального объема, а средневзвешенная доля экспорта в отгрузках предприятий составляет $3.9 \%$, что возможно объясняется недостаточным платежеспособным спросом на внутреннем рынке и низкой экспортной составляющей [10]. Соответственно производственные мощности предприятий отрасли настоящее время загружены на 40$70 \%$ (в зависимости от видов техники).

Также за рассматриваемый период времени произошло сокращение производства оборудования для добывающей промышленности по всем позициям: комбайны проходческие (шт.) - 12.3\% в 2009 г. отно- 
сительно 1990 г. и 7.1\% в 2016 г. относительно 1990 г.; подъемники и конвейеры непрерывного действия для подземных работ (шт.) - 52.7\% в 2016 г. относительно 2010 г.; установки буровые для эксплуатационного и глубокого разведочного бурения (комплектов) - 32.4\% в 2016 г. относительно 2010 г. Производство оборудования для добывающей промышленности зависит от состояния профильных отраслей. Рост российского рынка горно-строительной техники в последние годы замедлился в связи с экономическим кризисом. В 2017 г. темп роста добывающих отраслей снизился до $2.0 \%$ (с $2.7 \%$ в 2016 г.). Однако по данным Росстата в добывающей промышленности износ основных фондов составляет около $57.5 \%$ [11], в связи с этим в ближайшие годы возможен рост выпуска оборудования для данной отрасли.

Сокращение производства строительно-дорожной техники. наблюдается по всем показателям. Сводный индекс по всем позициям составил в 2016 г. 3\% относительно 1990 г. Минпромторг планирует к 2030 г. за счет сохранения действующих мер господдержки и внедрения новых механизмов увеличить долю продукции российских предприятий на внутреннем рынке с 45 до 80\% (в 2016 г. российский рынок строительно-дорожной техники составил порядка 150 млрд руб.).

В РФ практически прекращено производства оборудования для легкой промышленности: машины прядильные (шт.) - 0.8\% в 2009 г. относительно 1990 г.; станки ткацкие (шт.) - 0.07\% в 2009 г. относительно 1990 г. и $0.04 \%$ в 2016 г. относительно 1990 г. Основными причинами падения производства оборудования для легкой промышленности является неконкурентоспособность продукции легкой промышленности по цене, так как азиатские страны, имеют в достаточном количестве сырье и дешевую рабочую силу (доля отечественной продукции составляет в настоящее время не более $30 \%$ рынка). В то же время российские производители испытывают дефицит капитала на развитие и модернизацию предприятий, в связи с чем спрос на оборудование для легкой промышленности существенно снижается, однако и он компенсируется за счет импорта. Так, прядильные машины импортируются в Россию из следующих стран (2018 г.): Германия (35.5\%), Чехия (27.5\%), Турция (26.5\%), Китай (5.6\%), Италия (4.6\%), Новая Зеландия (0.3\%) [12].

Также наблюдается сокращение производства оборудования для пищевой промышленности: производства печей (включая кондитерские печи) хлебопекарных промышленных неэлектрических, кроме туннельных печей (шт.) - 35.8\% в 2016 г. по отношению к 2010 г. На развитие 
отечественного производства оборудования для пищевой промышленности влияет экономический спад в стране, однако в течение последних 10 лет в России вдвое увеличился импорт оборудования для пищевой и упаковочной промышленности, в первую очередь из Германии [13].

Выводы. Выполненные в работе расчеты выявили значительное падение производства практически по всем основным укрупненным направлениям обрабатывающей промышленности, в особенности в производстве машин и оборудования.

Проведенный анализ позволяет выделить следующие риски для экономической безопасности страны: рост зависимости внутренних товарных рынков от импорта; ухудшение структуры производства (спад промышленного производства, снижение доли обрабатывающей промышленности в ВВП); физическая изношенность и моральное устаревание материально-технической базы предприятий (средний показатель степени износа оборудования в среднем по экономике - 49\%; средний возраст используемых в промышленности машин и оборудования - более 13 лет, среди которых 28\% парка имеет возраст 15-30 лет, а 4\% - свыше 30 лет; в обрабатывающей промышленности уровень износа основных фондов в 2016 г. составил более 50\% (предельно критическое значение 40\%).

Более $75 \%$ российских предприятий обрабатывающей промышленности в настоящее время зависят от поставок импортного оборудования, около 30\% промышленных предприятий нуждаются в зарубежных технологиях, что усугубляет риски для технологической и промышленной безопасности страны в связи с санкциями из-за ограничения поставок металлообрабатывающего оборудования двойного назначения, запасных частей, компонентов, расходных материалов, инструмента и оснастки, увеличения сроков обслуживания и ремонта уже поставленного оборудования.

При разработке стратегии перехода к реиндустриализации, снижении рисков для экономической безопасности страны следует учитывать следующие конкурентные преимущества России: квалифицированная и относительно дешевая (по сравнению с ЕС) рабочая сила; развитые нефтедобывающая и нефтеперерабатывающая промышленность (сырье для ряда отраслей). 


\section{СПИСОК ЛИТЕРАТУРЫ}

1. Варшавский A.E. Макро- и микроэкономические проблемы реиндустриализации России: пути решения // Экономическое возрождение России. 2018. №1 . c.23-32.

2. Варшавский A.E. Ускоренная деиндустриализация Москвы: основные проблемы и последствия // Научно-практический журнал "Конщепщии". 2018. №1 (37). c.78-95.

3 . Корнев А.К. Реиндустриализации отечественной рыночной экономики - peзерв ее роста // Анализ и моделирование экономических и социальных процессов: Математика. Компьютер. Образование. 2018. Т. 25, № 6. С. 23-37.

4. Макарова Ю.А. Оценка военного капитала России // Научно-практический журнал "Кониепиии". 2017. №1 (36). с.48-53.

5. Rodrik D. Premature deindustrialization. Springer Science+Business Media New York. Published online: 27 November 2015. DOI: 10.1007/s10887-015-9122-3/

6. Российский статистический ежегодник. 1990-2017. URL: http://www.gks.ru

7. Пока в догоняющих: о производстве насосов // Сетевое издание «STROYPULS». № 171 октябрь 2016. URL: http://stroypuls.ru/pso/2016/171-oktyabr-2016-2016/127199

8. Рынок лифтов в России - 2018. Показатели и прогнозы / TEBIZ GROUP. 20 февраля 2018.

9. Стратегия развития сельскохозяйственного машиностроения России на период до 2030 года. URL: http://minpromtorg.gov.ru/common/upload/files/strategy_tll2030.pdf

10. Данные Минпромторга России на основе проведенного анкетирования 53 предприятий Сельхозмашиностроения. URL: http://minpromtorg.gov.ru

11. Александр Трушин о самой дорогой российской болезни - изношенности оборудования. URL: https://www.kommersant.ru/doc/3566436

12. Экспорт и импорт России по товарам и странам.

URL: http://ru-stat.com/date-M201705-201805/ru/import/cn/16844520

13. Обзор пищевой и упаковочной промышленности России.

URL: http://chinamachineryfair.ru/russia-foodprocessingandpackaging

\section{ANALYSIS OF RISKS OF DEINDUSTRIALIZATION IN RUSSIA}

\section{Komkina T.A.}

The aim of the work is to analyze the development of the main integrated areas of the manufacturing industries in Russia in order to identify the risks caused by deindustrialization. 